Article

\title{
Multi-Color Spectral Transcript Analysis (SPECTRA) for Phenotypic Characterization of Tumor Cells
}

\author{
Joanne H. Hsu ${ }^{1,2, *}$, Jingly F. Weier ${ }^{2,3}$, Heinz-Ulrich G. Weier ${ }^{2}$ and Yuko Ito ${ }^{4}$
}

1 Fred Hutchinson Cancer Research Center, 1100 Fairview Avenue North, Seattle, WA 98109, USA;

2 Life Sciences Division, E.O. Lawrence Berkeley National Laboratory, 1 Cyclotron Road, Berkeley, CA 94720, USA; E-Mail: ugweier@lbl.gov (H.U.G.W.)

3 Department of Pathology, University of California, San Francisco (UCSF), CA 94143, USA; E-Mail: jinglyw@gmail.com (J.F.W.)

4 National Institute of Science and Technology Policy (NISTEP), Ministry of Education, Culture, Sports, Science and Technology, Tokyo 100-0005, Japan; E-Mail:itoh@nistep.go.jp (Y.I.)

* Author to whom correspondence should be addressed; E-Mail: jhhsu11@gmail.com; Tel.: +001-925-376-5188; Fax: +001-206-667-5255.

Received: 9 January 2013; in revised form: 31 January 2013 / Accepted: 4 February 2013 / Published: 11 February 2013

\begin{abstract}
Many human tumors show significant changes in their signal transduction pathways and, thus, the way the cells interact with their environment. Often caused by chromosomal rearrangements, including gene amplifications, translocations or deletions, the altered levels of gene expression may provide a tumor-specific signature that can be exploited for diagnostic or therapeutic purposes. We investigated the utility of multiplexed fluorescence in situ hybridization (FISH) using non-isotopically labeled cDNA probes detected by Spectral Imaging as a sensitive and rapid procedure to measure tumor-specific gene expression signatures. We used a commercially available system to acquire and analyze multicolor FISH images. Initial investigations used panels of fluorescent calibration standards to evaluate the system. These experiments were followed by hybridization of five-to-six differently labeled cDNA probes, which target the transcripts of tyrosine kinase genes known to be differently expressed in normal cells and tumors of the breast or thyroid gland. The relatively simple, yet efficient, molecular cytogenetic method presented here may find many applications in characterization of solid tumors or disseminated tumor cells. Addressing tumor heterogeneity by means of multi-parameter single cell analyses is expected to enable a wide range of investigations in the areas of tumor stem cells, tumor clonality and disease progression.
\end{abstract}


Keywords: cancer; gene expression; tyrosine kinase; fluorescence in situ hybridization (FISH); spectral imaging

\section{Introduction}

The field of molecular cytogenetic technology is comprised of various approaches to determine the chromosomal make-up of diploid cells, spermatocytes or polar bodies in research and clinical practice. While the chromosomal analysis using fluorescence in situ hybridization (FISH) has dominated the field for many years, DNA microarray-based assays have gained popularity in recent years due to the fact that they are relatively easy to automate and offer superb resolution. Our laboratory has been adapting DNA microarray technology to identify genes involved in the onset and progression of endocrine tumors in the thyroid, breast and prostate. Not too long ago, the expression levels of only a few genes could be assayed in a single experiment. The cDNA microarrays now circumvent this limitation [1,2]. However, problems related to tumor heterogeneity limit our progress in cancer research. Most tumors represent a mixture of different cell types, due to the normal complexity of the tissue, which includes aneuploidy and somatic genomic variation [3,4], as well as the complexity of tumors as they evolve from benign lesions to the more malignant, metastatic neoplasms [3,5-11]. If researchers collect microarray data without confronting the problem of tumor or tissue heterogeneity, important correlations (e.g., between the spatial or temporal expression of several genes and the tumor or disease stage) might be missed $[2,5,12]$.

Preliminary studies performed in many laboratories indicated that a majority of solid tumors are heterogeneous in regards to cellular oncogene expression. To be able to assess intercellular variability, these studies were often performed using FISH with touching imprint preparations of tumor cells (so-called 'touch preps') and filter-based microscope systems [13,14]. Typically, no more than two or three fluorescently tagged hybridization probes were used per experiment [2]. When more expressed sequences had to be analyzed, additional slides from the same specimens had to be hybridized.

The quantitative PCR and filter-based RNA FISH approaches reported previously [15,16] may work well for homogeneous cell cultures, but they do not allow study of the correlation between the expression levels of five or more genes, if the cells of interest are relatively rare or genes are expressed at vastly different levels from one cell to another [17].

Spectral imaging, on the other hand, offers superior resolution and additional choices for probe labels than the filter-based microscope imaging systems [18-23]. This approach is based on exciting the fluorochromes simultaneously in several different wavelength intervals using a custom designed polychromatic mirror and replacing the fixed wavelength bandpass filters in the microscope's emission path with a combination of a custom multiband emission filter and an interferometer (Sagnac interferometer) [18,24,25]. Commonly referred to as 'Fourier spectroscopy', interferograms for all points in the image plane are generated by dividing the light entering the Sagnac interferometer into two beams that travel paths of slightly different lengths before combining the beams at the interferometer exit [24]. A camera attached to the microscope port records a series of resulting interferograms, while the optical path difference is changed stepwise. Next, a spectral image, i.e., a 
stack of monochrome images representing the image intensities as a function of the wavelength, are calculated on a personal computer for all points in the image by a straightforward mathematical operation called 'Fourier transformation' [23,24].

Spectral imaging systems have been used extensively to study structural and numerical chromosome alterations [25-33]. If the objects are physically separated, such as the chromosomes in metaphase spreads, probes labeled with different combinations of fluorescent reporter molecules can be hybridized to uniquely decorate the target chromosomes. Each of the 24 human chromosome types (i.e., the 22 autosomes, $\mathrm{X}$ and $\mathrm{Y}$ ), for example, can then be unambiguously identified by comparing the measured spectrum along each chromosome with a pre-recorded library of reference spectra [26]. This technique, termed 'spectral karyotyping (SKY)', has been applied very successfully to identify translocations and marker chromosomes in tumor samples and prenatal diagnosis [26,27,29-31,33]. Whole chromosome painting probes labeled with chromosome-specific combinations of up to five reporter molecules are commercially available, thereby greatly facilitating the identification of marker chromosomes and cryptic translocations in the clinical practice [34].

The work of Fung et al. [28,32] extended the application of spectral imaging (SIm) to the analysis of interphase cell nuclei. Chromosome-specific DNA repeat probes and single copy DNA probes labeled with combinations of six reporter molecules allowed the routine enumeration of 10 different chromosome types in single blastomere cells from human preimplantation embryos [28]. The analysis using such 'combinatorial labeled probes' [35], however, becomes much more difficult when hybridization domains overlap spatially [32]. Multicolor FISH (mFISH) and SKY or SIm meet their limitations [36-38], especially when it comes to the issues of sensitivity and signal flaring or blending caused by probe co-localization, but we felt the advantages of SIm in regard to fluorochrome identification outweigh the acquisition speed advantages of filter-based mFISH systems [19,39].

The short-term goal of the present study was the development and thorough evaluation of an affordable, molecular cytogenetics-driven, microscope-based system to quantitatively assess the expression levels of five or six genes of interest. With a research focus on thyroid and breast neoplasms, we selected a panel of genes known to independently alter their relative levels of RNA expression when normal cells undergo malignant transformation or tumors progress.

With the measurement of intratumoral heterogeneity in mind, we decided to develop a SIm-based analytical technology platform for single cell gene expression profiling that uses gene-specific cDNA probes labeled with individual, distinguishable reporter molecules. Our multi-color 'Spectral Transcript Analysis (SPECTRA)' uses fluorochromes that can be distinguished based on significant differences in their emission spectrum. Spatial overlap, an important issue, since most of the target RNA molecules might be found in the cell's cytoplasm and ribosomes, is addressed by a technique termed 'spectral un-mixing' [22,23,25]. Here, we describe the principle components of our SPECTRA system and demonstrate its application for the semi-quantitative analysis of five-to-six tyrosine kinase (tk) RNA species in breast or thyroid epithelial cells. 


\section{Results and Discussion}

\subsection{System Evaluation Using Fluorescent Beads}

The Inspeck ${ }^{\mathrm{TM}}$ beads commercially available from Invitrogen (Carlsbad, CA) appeared to be better suited than hybridized tumor cells to analyze instrument functions, because they showed a much lower degree of fading in repeated scans. Particle concentrations were adjusted so that a typical field of view contained about 20-50 objects. Results indicated that the spectral imaging software delivers virtually identical results when repeatedly analyzing the same image.

The reproducibility of analyzing the same field of view was investigated by moving the stage after each recording of eleven spectral images. Briefly, analyzing beads located in the center of the images, we found relative standard deviations ranging from $2 \%-5 \%$. The higher variation values were attributed to inappropriate lateral positioning or the out-of-focus location of beads.

We tested the reproducibility of multi-color fluorescence measurements with fluorescent beads, because they were less affected by photo-bleaching than our hybridized cells. Spectral Images were recorded in a range of $450 \mathrm{~nm}$ to $800 \mathrm{~nm}$ with a resolution of about 10nm. We prepared slides carrying either five types of beads listed in the Experimental Section or just the four types of Inspeck ${ }^{\mathrm{TM}}$ beads (Figure 1), i.e., not using beads with fluorescence emission in the infrared wavelength interval. The reproducibility of measuring the fluorescence spectra of objects was first investigated by recording repeated pictures of the same area without moving the microscope stage and then by moving the microscope stage back-and-forth between the recordings of spectral images. Analysis of beads located in the various parts of the images showed relative standard deviations of $1 \%-6 \%$ for measurements of beads in the $2.5 \mu \mathrm{m}$ size range, while measurements of smaller $(1 \mu \mathrm{m})$ beads showed greater variability. The higher variation values were attributed to difficulties in defining the regions of interest and out-of-focus location of beads. As the following results show, average coefficients of variation (CVs) for beads in the relevant size range were well under 4\%. Thus, the system possesses the desired reproducibility.

Figure 1. Four-color Inspeck ${ }^{\mathrm{TM}}$ beads used to test the reproducibility of the system. The settings for this false-color image display were blue $=475-557 \mathrm{~nm}$, green $=561-635 \mathrm{~nm}$ and red $=635-752 \mathrm{~nm}$. The arrows point to non-overlapping signals that were analyzed. Beads 3, 5, 6 and 7 fluoresced in red.

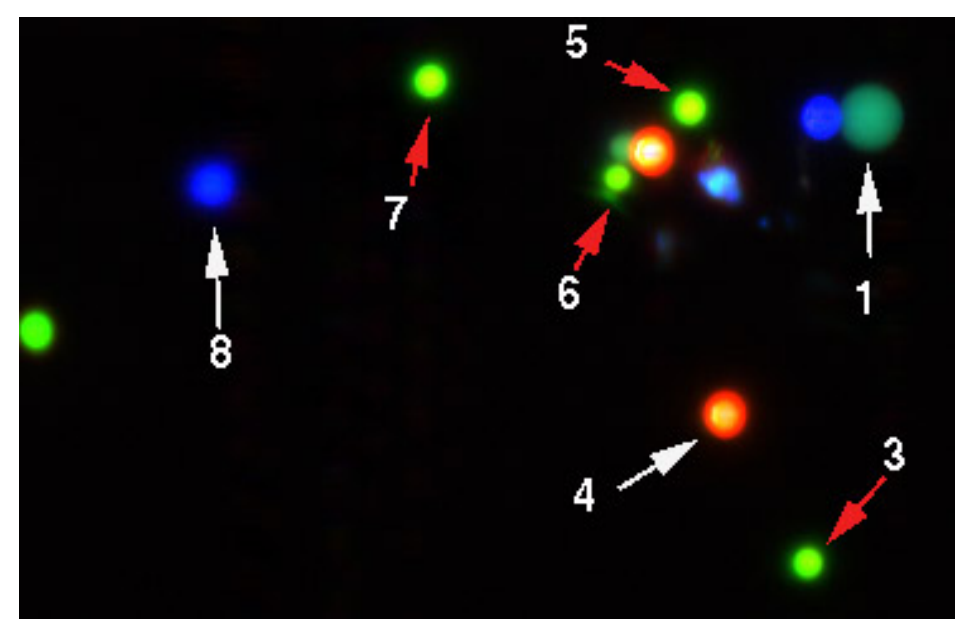




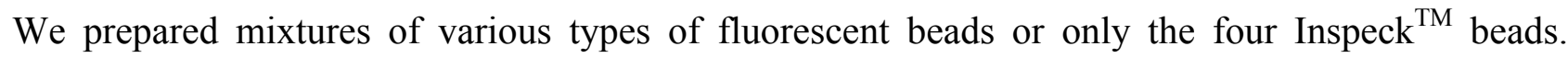
Typically, $2-3 \mu \mathrm{L}$ of liquid containing the beads were placed on ethanol cleaned microscope slides and covered with a $22 \mathrm{~mm} \times 22 \mathrm{~mm}$ coverslip. Since the slides had a tendency to dry quickly, images were recorded within 24 hours after preparation. When analyzing slides carrying all five types of beads, a typical field of view contained about 50-60 objects. Smaller areas, such as the field shown in Figure 1, were selected for quantitative analysis.

We prepared a mixture of the four Inspeck ${ }^{\mathrm{TM}}$ beads and recorded eleven images. The microscope stage was moved manually between recordings. We analyzed nine of the eleven images, because image AQ1 did not contain all beads and image AQ7 was out of focus. Figure 1 shows a typical false-color image of various beads. The numbers refer to the beads analyzed.

Table 1 shows the results of our analysis. For each of four beads, Table 1 reports the region-of-interest (ROI) area and average fluorescence per pixel in the relevant spectrum. The column 'total' shows the total amount of fluorescence (area $X$ average intensity per pixel) in the ROI. Table 1 compares the fluorescence emission of four differently colored beads, i.e., beads 1 (orange), 4 (red), 7 (deep red) and 8 (green), in the nine images analyzed. Relative standard deviations range from $2.5 \%$ to $6.1 \%$ (average $4.05 \%$ ). The analysis of four red-to-infrared fluorescent beads (beads 3, 5, 6 and 7) (Experimental Section 3.1.) showed less variation. For the red fluorescent beads, relative coefficients of variation ranged from $1.0 \%$ to $4.0 \%$, with an average of $2.3 \%$ (data not shown).

In summary, the spectral imaging system allowed us to separate complex fluorescence spectra into up to five or six constituents (as shown further below) and to determine the relative contribution of each of the constituents with high reproducibility. Thus, the system meets the specifications required for multiple gene expression profiling.

Table 1. Reproducibility of fluorescence measurements using fluorescent beads.

\begin{tabular}{|c|c|c|c|c|c|c|c|c|c|c|c|c|}
\hline \multirow[b]{2}{*}{ Image } & \multirow[b]{2}{*}{ area } & \multirow{2}{*}{$\begin{array}{c}\text { Bead } 1 \\
\text { int* }\end{array}$} & \multirow{2}{*}{$\begin{array}{l}\text { (orange) } \\
\text { total }\end{array}$} & \multicolumn{3}{|c|}{ Bead 4 (red) } & \multicolumn{3}{|c|}{ Bead 7 (deep red) } & \multicolumn{2}{|r|}{ Bead 8} & \multirow{2}{*}{$\begin{array}{l}\text { (green) } \\
\text { total }\end{array}$} \\
\hline & & & & area & int* & total & area & int* & total & area & int* & \\
\hline AQ2 & 667 & 614 & 409527 & 742 & 880 & 652621 & 381 & 780 & 297024 & 564 & 837 & 471995 \\
\hline AQ3 & 649 & 618 & 400866 & 727 & 876 & 637152 & 471 & 637 & 300199 & 737 & 636 & 469043 \\
\hline AQ4 & 687 & 588 & 403777 & 587 & 1051 & 616654 & 715 & 452 & 323468 & 871 & 541 & 471641 \\
\hline AQ5 & 693 & 563 & 389916 & 779 & 808 & 629618 & 537 & 569 & 305399 & 872 & 527 & 459167 \\
\hline AQ6 & 668 & 593 & 396191 & 830 & 748 & 621142 & 567 & 533 & 302220 & 963 & 466 & 448615 \\
\hline AQ8 & 836 & 472 & 394217 & 946 & 649 & 613862 & 709 & 438 & 310848 & 1048 & 408 & 427834 \\
\hline AQ9 & 777 & 480 & 373217 & 885 & 669 & 592318 & 721 & 422 & 304085 & 1046 & 394 & 412043 \\
\hline AQ10 & 763 & 481 & 367255 & 862 & 683 & 588488 & 720 & 420 & 302676 & 1160 & 361 & 419221 \\
\hline AQ11 & 772 & 473 & 365526 & 1037 & 583 & 604999 & 745 & 412 & 307050 & 1070 & 378 & 404067 \\
\hline \multicolumn{2}{|c|}{ Average } & & 388944 & & & 617428 & & & 305886 & & & 442625 \\
\hline \multicolumn{3}{|c|}{ Standard Deviation } & 16330 & & & 20694 & & & 7691 & & & 27158 \\
\hline \multicolumn{3}{|c|}{ C.V. [\%] } & 4.2 & & & 3.4 & & & 2.5 & & & 6.1 \\
\hline
\end{tabular}

* The 'int' is the average intensity per pixel.

\subsection{Gene Expression Analysis of Cancer Cell Lines}

Key to the success of RNA fluorescence in situ hybridization (FISH) is to maintain an essentially RNase-free environment. We achieved this by pretreating all solutions with DEPC, while glassware used in the experiments was pretreated with an RNase inhibitor.

Using the five fluorochromes (FITC, Cy3, Texas Red, Cy5 and Cy5.5) we were able to label, detect and quantitate specific gene transcripts in individual cells. The example in Figure 2 demonstrates the 
typical spectral analysis of MCF-7 breast cancer cells hybridized with individually labeled cDNA probes against five different tyrosine kinase gene transcripts (homo sapiens PTK6 protein tyrosine kinase 6 (PTK6), ephrin receptor a2 (EFNA2), homo sapiens lymphocyte-specific protein tyrosine kinase (LCK), homo sapiens mitogen-activated protein kinase kinase kinase 11 (MAP3K11) and homo sapiens CDC-like kinase 3 (CLK3)). The deconvoluted or 'spectrally un-mixed' images showing the distribution of fluorochromes within cells indicate gene-specific RNA levels and spatial distributions (Figure 2, bottom). For the display, false colors were assigned to the reporter molecule images, as indicated in the box 'Fluorescent SUN' in the upper right corner of Figure 2. The image labeled 'Current Result View' in the lower left corner shows a pseudo-RGB image of fluorescent signals prior to spectral un-mixing (SUN). A 4',6-diamidino-2-phenylindole (DAPI) image showing the location of cell nuclei was included in Figure 2 for reference. The next steps of expression analysis involved the definition of regions-of-interest (ROI) and calculation of the amount of fluorescence per dye per cell.

Figure 2. The spectral analysis of MCF-7 cells that were deposited on glass slides and hybridized with the probe mixture listed in Section 3.3. Following background subtraction, the fluorescence spectra emitted from each region-of-interest (ROI) were separated into their five constituents, shown in the five small windows labeled FL-1 to FL-5 at the bottom of the figure. The library files, i.e., prerecorded spectra, used for spectral un-mixing ('SUN') are highlighted in the small window in the upper right corner labeled 'Fluorescent SUN'.

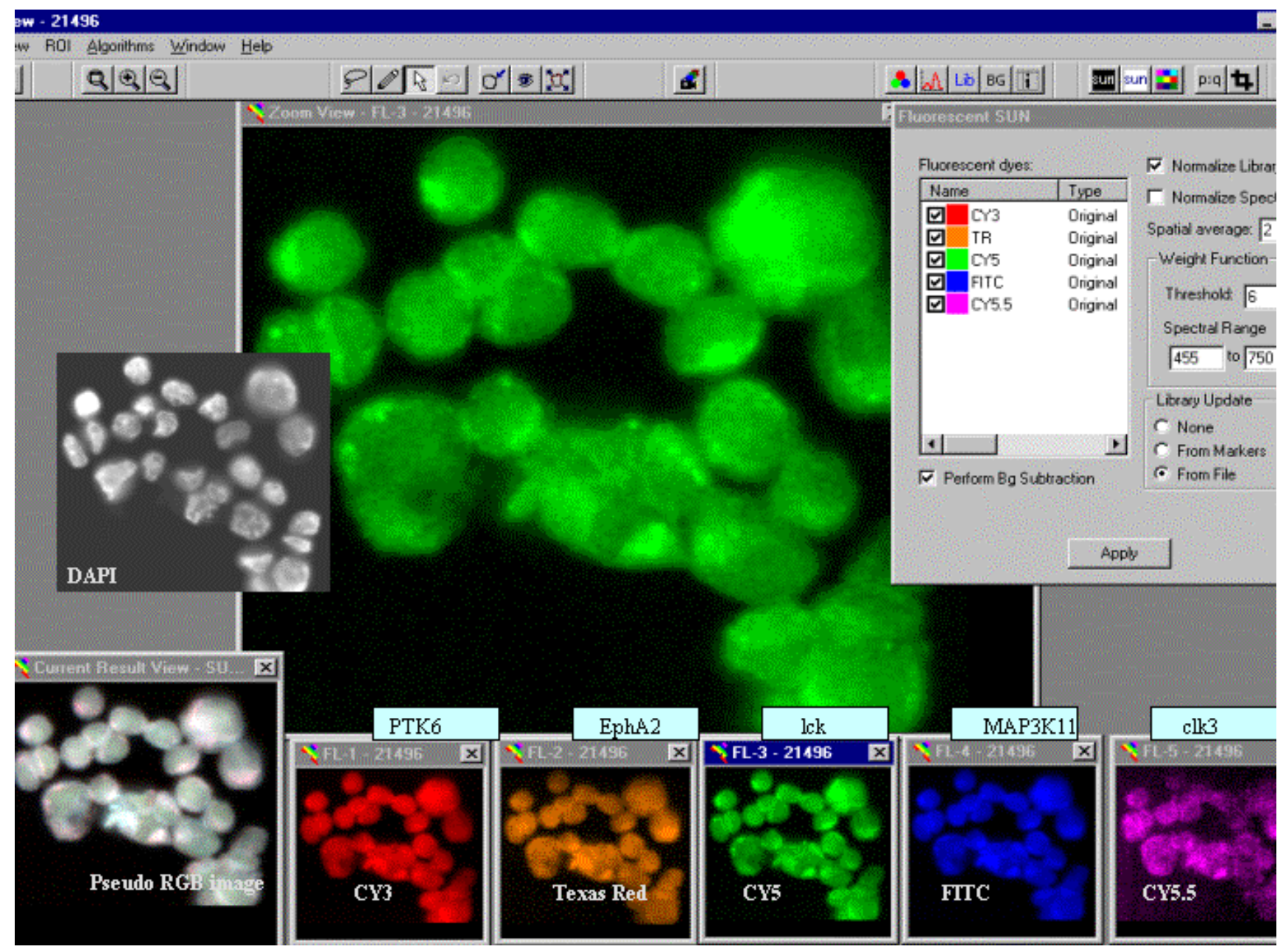


We found that in non-synchronized cell cultures, gene expression levels were affected by the cell cycle position. When measuring the relative amounts of probes bound per cell, however, we were able to discriminate cells from different lines. Future studies will be needed to address the issues of ratio imaging and internal standards.

We created artificial mixtures of paraformaldehyde (PFA)-fixed MCF-7 (breast cancer) cells and TPC-1 (thyroid cancer) cells that were placed on cleaned glass slides for hybridization. Preliminary studies using poly-L-lysine coated or silanated slides, however, lead to unacceptable levels of background fluorescence. After cell counts were taken with a hemocytometer, we mixed PFA-fixed MCF-7 and TPC-1 cells at ratios of 1:1 and 100:1. In spite of our best efforts to minimize clumping of cells, the cells did stick together to a degree. Therefore, our cell mixture ratios were not precise and, dependant on the field of view, were found to vary by up to a factor of three to four. We opted not to use excessively vigorous measures to break up these clumps to preserve the structural integrity of our cells. Several thousand cells from a given cell mixture were spotted on a glass microscope slide and allowed to dry above a $90{ }^{\circ} \mathrm{C}$ hot plate. The slides did not contact the hot plate, but the additional heat evaporated the water more quickly. Each spot consisting of a mixture of cells was flanked by two spots consisting of each cell type alone. All spots had approximately the same number of cells. The slidebound cells were then subjected to our hybridization protocol.

Our analytical procedures included a definition of reference spectra obtained from slides hybridized with just one probe at a time, definition of ROI's, subtraction of background fluorescence and SUN. A typical example, i.e., the analysis of image Y124M-5, is shown in Figure 3. Our nomenclature is simple: this image depicts the analysis of the $124^{\text {th }}$ slide prepared by Dr. Y. Ito, and we are looking at the fifth image recorded from cells deposited in the middle spot. This slide (Y124) contained one spot each of pure MCF-7 and TPC-1 cells to the left (Y124L) and right (Y124R), respectively, and a 50:50 ratio of these cell lines in the spot in the middle. Spectral analysis showed a cluster of seven MCF-7 cells next to two TPC-1 cells (Figure 3).

The high level of FITC fluorescence emitted from MCF-7 cells stems from the cDNA probe used in these experiments. Our RET/PTC probe was a chimeric cDNA clone isolated in Dr. S. Jhiang's lab (Ohio State University, Columbus, OH) from a tumor carrying a RET/PTC3 rearrangement [40]. In the rearrangement, the 3'-end of the RET gene containing the entire tyrosine kinase domain is fused to the 5 '-end of a constitutively expressed gene (called 'ELE1' or 'RFG') [10,40]. The FITC fluorescence measured in MCF-7 cells is believed to represent the ELE1 portion of the probe plus any amount of autofluorescence not removed by the background subtraction. To eliminate this cross-reactivity, we plan to isolate only the 3'-end of the RET/PTC3 cDNA clone to be used as a probe in further investigations.

The breast cancer cells, on the other hand, show higher levels of ABL and PTK6, which comes as no surprise, since the latter was first reported to be expressed at high levels in breast cancer tissues. The analysis of additional images consistently showed that TPC-1 cells expressed higher levels of RET and lower levels of ABL. 
Figure 3. The spectral analysis of mixed cell samples. MCF-7 and TPC-1 cells were mixed, deposited on glass slides and hybridized with the six probe mixture listed in Section 3.3. Following background subtraction, the fluorescence spectra emitted from each ROI were separated into their constituents (shown in Table 2, below). The results are shown in the small window labeled 'ROI Information' in the upper right corner. The Figure shows five windows (FL-1 to FL-5) with cDNA fluorescence in situ hybridization (FISH) results.

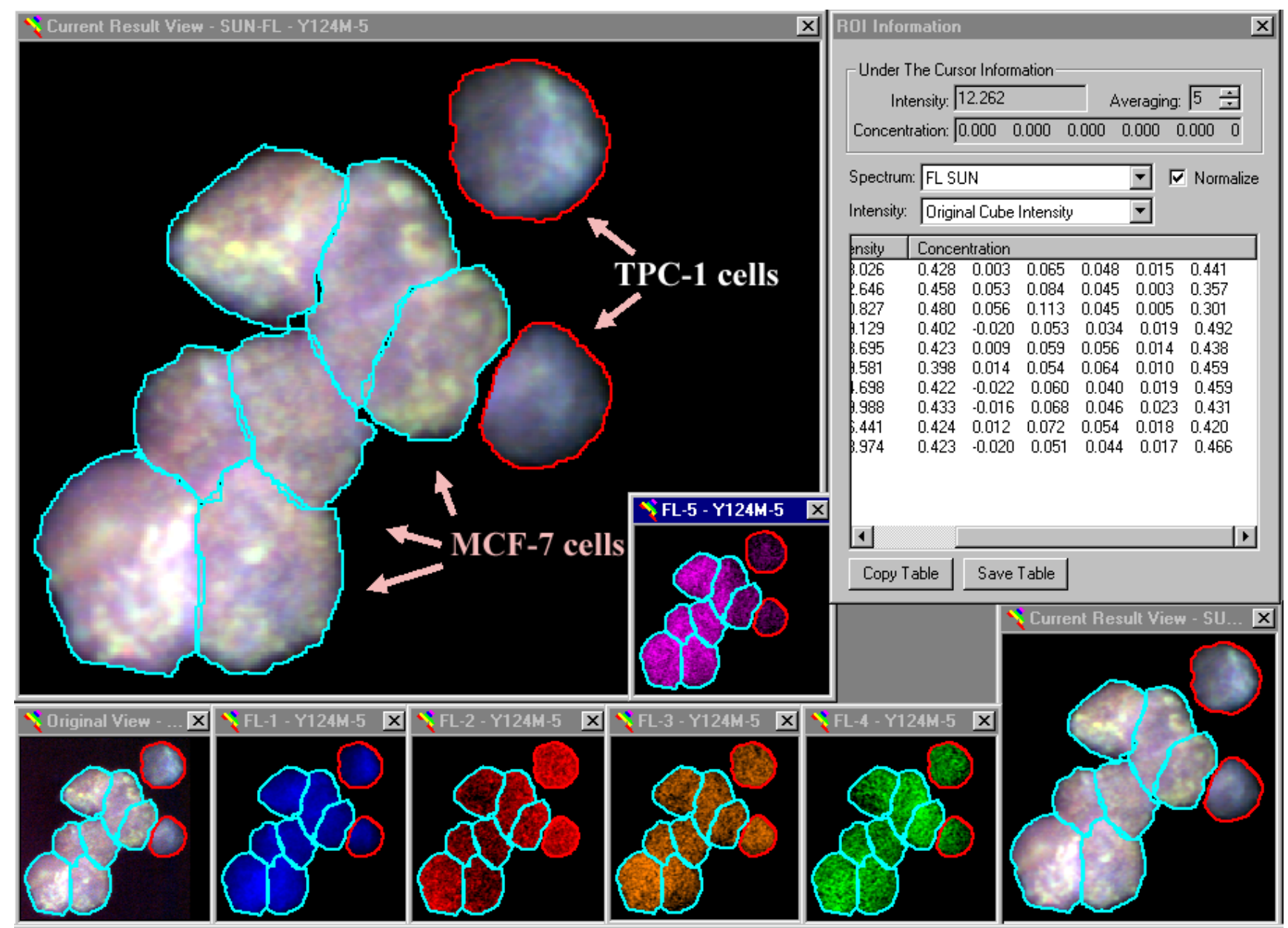

Table 2. Relative levels of six fluorescent reporters used to tag RNA species.

\begin{tabular}{llllllllll}
\hline & & & RET & EFNA1 & EFNA4 & RON & PTK6 & v-ABL & Cell \\
ROI & Area & Int* & FITC & Cy3 & TR & Cy5 & Cy5.5 & Cy3.5 & Type \\
\hline 1 & 3482 & 143 & 45.8 & 5.3 & 8.4 & 4.5 & 0.3 & 35.7 & TPC-1 \\
2 & 2358 & 121 & 48.0 & 5.6 & 11.3 & 4.5 & 0.5 & 30.1 & TPC-1 \\
3 & 3830 & 209 & 40.2 & -2.0 & 5.3 & 3.4 & 1.9 & 49.2 & MCF-7 \\
4 & 3607 & 214 & 42.3 & 0.9 & 5.9 & 5.6 & 1.4 & 43.8 & MCF-7 \\
5 & 2897 & 200 & 39.8 & 1.4 & 5.4 & 6.4 & 1.0 & 45.9 & MCF-7 \\
6 & 2902 & 205 & 42.2 & -2.2 & 6.0 & 4.0 & 1.9 & 45.9 & MCF-7 \\
7 & 2155 & 190 & 43.3 & -1.6 & 6.8 & 4.6 & 2.3 & 43.1 & MCF-7 \\
8 & 4988 & 236 & 42.4 & 1.2 & 7.2 & 5.4 & 1.8 & 42.0 & MCF-7 \\
9 & 4167 & 219 & 42.3 & -2.0 & 5.1 & 4.4 & 1.7 & 46.6 & MCF-7 \\
\hline
\end{tabular}

* Fluorescence levels are reported in percent of total cellular fluorescence in image Y124M-5, recorded from a mixture of TPC-1 and MCF-7 cells 
2.3. Detection of Rare Cells that Differ in Target Gene Expression by 50\% or More from the Majority of Cells

We used the above mentioned 1:100 mixture of TPC-1 and MCF-7 cells to investigate the system's ability to detect rare events. Due to an inversion on chromosome 10q, which leads to expression of a chimeric RET/PCT1 transcript [40], TPC-1 cells are expected to express the RET gene at a much higher level than MCF-7 cells. Following hybridization, we recorded eleven images containing 79 cells. One of the images could not be analyzed, because it was recorded with mismatched filters. Visual inspection of the ten fields of view prior to image acquisition had suggested the possibility that two of them might contain one or two TPC-1 cells, and one image contained a large cluster of green fluorescent cells. Spectral analysis revealed that the clusters of cells in some images were comprised entirely of TPC-1 cells, while other images contained only MCF-7 cells (data not shown).

In conclusion, the spectral imaging system and digital imaging processing are capable of detecting rare cell that differ in target gene expression by $50 \%$ or more from the majority of cells. Artificial mixing experiments using TPC-1 and 184A1TH cells [41] showed similar results (data not shown).

\section{Experimental Section}

\subsection{Fluorescent Beads}

We used fluorescent beads (Inspeck ${ }^{\mathrm{TM}}$; Invitrogen) to test the reproducibility of the system. Inspeck $^{\mathrm{TM}}$ beads are available in different absorbance/fluorescence wavelength intervals, in different sizes, as well as with different average amounts of dye load. In the experiments described above, we used four different colors (green orange, red, deep red) of either $2.5 \mu \mathrm{m}$ or $6 \mu \mathrm{m}$ beads loaded with either $0 \%, 1 \%, 3 \%, 10 \%$ or $100 \%$ of the respective fluorochrome to evaluate our system. The bead types can easily be distinguished by eye. Table 3 lists the Inspeck $^{\mathrm{TM}}$ beads that we used in our experiments and the fluorescence characteristics of 3 types of calibration standard beads that fluoresce in the infra-red wavelength region. All system-specific reference spectra for Inspeck $^{\mathrm{TM}}$ beads and infrared dyes were generated from background fluorescence-corrected spectral images of individual beads and saved as library files to make them available for the analysis of additional images.

Table 3. Fluorescent beads used to evaluate components of the SPECTRA system.

\begin{tabular}{|c|c|c|c|c|}
\hline Color & Type & Size & $\begin{array}{c}\text { Excitation } \\
{[\mathrm{nm}]}\end{array}$ & $\begin{array}{c}\text { Emission } \\
\text { [nm] }\end{array}$ \\
\hline Green & Inspeck $^{\mathrm{TM}}$ & 2.5 micron & 505 & 515 \\
\hline Orange & Inspeck $^{\mathrm{TM}}$ & 2.5 micron & 540 & 560 \\
\hline Red & Inspeck $^{\mathrm{TM}}$ & 2.5 micron & 580 & 605 \\
\hline Deep Red & Inspeck $^{\mathrm{TM}}$ & 2.5 micron & 633 & 660 \\
\hline Crimson & Fluosphere $^{\mathrm{TM}}$ & 1 micron & 625 & 645 \\
\hline Scarlet & Fluosphere $^{\mathrm{TM}}$ & 15 micron & 645 & 680 \\
\hline Ultra Red & Peakflow $^{\mathrm{TM}}$ & 6 micron & 665 & 695 \\
\hline
\end{tabular}




\subsection{Tissue Specimens}

The MCF-7 cells (ATCC, Rockville, MD) and 184A1TH cells [41] were grown in a medium consisting of DME H-16 50\%/F-12 50\% mix, 10\% fetal calf serum, 1\% penicillin/streptomycin $(100 \%$ is $10,000 \mu \mathrm{g} / \mathrm{mL}$ streptomycin plus 100 units $/ \mathrm{mL}$ penicillin) and insulin $(4 \mu \mathrm{g} / \mathrm{mL}$ at 0.024 units $/ \mu \mathrm{g}$ ). TCP-1 cells [42] were grown in Minimal Essential Medium (MEM) Alpha medium with L-glutamine (Invitrogen, La Jolla, CA, USA), 5\% fetal calf serum (Invitrogen) and 1\% penicillin/streptomycin. Prior to fixation, the cells were grown in T75 culture flasks (Corning Inc., Corning, NY, USA) to about $80 \%$ confluence and then trypsinized using $0.5 \mathrm{mg} / \mathrm{mL}$ trypsin in $0.2 \mathrm{~g} / \mathrm{L}$ EDTA (Invitrogen), $1.0 \mathrm{~g} / \mathrm{L}$ glucose, $0.58 \mathrm{~g} / \mathrm{L} \mathrm{NaHCO} 3$ (UCSF Tissue Culture Facility, San Francisco, CA, USA). Clumps were broken up by repeated pipetting. The cells were then pelleted in a clinical centrifuge at 1,000 rpm for 5 minutes, and the supernatant was removed. Cell pellets were resuspended in freshly prepared 4\% PFA (weight-to-volume) in phosphate-buffered saline (PBS), pH 7.4, and incubated for 15 minutes at room temperature. Sensitive in situ hybridizations of DNA probes to intracellular RNA targets rely on an RNAse-free environment during and after fixation. To eliminate RNAses, all glassware used was treated with RNase Zap (Ambion, Austin, TX, USA), and all solutions were treated with diethylpyrocarbonate (DEPC; Sigma, St. Louis, MO, USA). Having completed a 15 minute incubation in PFA fixative, the cells were pelleted at 1,000 rpm for 5 minutes. The supernatant was then removed, and the cells were washed three times for 15 minutes each with RNAse-free PBS followed by centrifugation and supernatant removal. Finally, cells were resuspended in RNAse-free PBS at a convenient concentration to drop onto glass slides.

\subsection{Fluorescence in situ Hybridization}

We developed a five cDNA probe, six-color in situ hybridization protocol to semi-quantitatively analyze the intracellular contents of five potentially oncogenic RNA species (Table 4). Commercially available cDNAs (Research Genetics, Huntsville, AL, USA) were labeled by random priming. Table 4 show the labeling scheme and fluorescence characteristics.

Table 4. Six-color, five transcripts spectral analysis.

\begin{tabular}{lcccc}
\hline RNA/DNA Target & Primary label & Secondary label & $\begin{array}{c}\text { Excitation } \\
{[\mathbf{n m}]}\end{array}$ & $\begin{array}{c}\text { Emission } \\
{[\mathbf{n m}]}\end{array}$ \\
\hline MAP3K11 & Biotin & FITC & 495 & 528 \\
PTK6 & Cy3 & -- & 552 & 565 \\
EFNA2 & Texas Red & -- & 596 & 620 \\
LCK & Cy5 & -- & 650 & 667 \\
CLK3 & Digoxigenin & Cy5.5 & 678 & 703 \\
Genomic DNA & DAPI & -- & 363 & 461 \\
\hline
\end{tabular}

The five color labeling scheme was designed to match the filters and mirror the spectral imaging system (Applied Spectral Imaging, Ltd. (ASI), Carlsbad, CA, USA). These were filters designed for use in SKY experiments (ChromaTechnology, Bellows Falls, VT, USA) using whole chromosome painting probes (ASI). Probe DNA were isolated from overnight cultures of the cDNA clones 2189231 
and 966003 probes (Research Genetics) using the GenElute plasmid miniprep kit (Sigma), according to the manufacturer's instructions. The inserts of the other three cDNA clones were amplified by PCR using vector-specific primers. PCR conditions were as follows: denaturation at $92{ }^{\circ} \mathrm{C}$ for 1 min, primer annealing at $42{ }^{\circ} \mathrm{C}$ for $2 \mathrm{~min}$ and extension at $72{ }^{\circ} \mathrm{C}$ for $3 \mathrm{~min}$ for a total of 25 cycles. The PCR products were precipitated in 1.5 volumes of 2-propanol and resuspended in one fifth of the PCR volume. We incorporated one of five different reporter molecules (biotin, Cy3, Texas Red, Cy5 and digoxigenin) into our probe cDNAs by random priming using a commercially available kit (BioPrime $^{\mathrm{TM}}$, Invitrogen). The cDNA labeling and detection scheme is shown in Table 4. We combined $0.5 \mu \mathrm{L}$ of each cDNA probe with $1 \mu \mathrm{L}$ salmon sperm DNA (20 mg/ml; 3'-5', Boulder, CO) and $1 \mu \mathrm{L}$ human $\mathrm{COT} 1^{\mathrm{TM}} \mathrm{DNA}$ (Invitrogen), before $7 \mu \mathrm{L}$ of hybridization master mix [(78.6\% FA), $14.3 \%$ dextran sulfate in $2.9 \times$ saline-sodium citrate $(\mathrm{SSC})$ buffer, $\mathrm{pH} 7.0(1 \times \mathrm{SSC}$ is $150 \mathrm{mM} \mathrm{NaCl}$, $15 \mathrm{mM}$ Na citrate))], were added. This gave a total hybridization mixture of $11.5 \mu \mathrm{L}$.

The hybridization mixture was denatured at $91{ }^{\circ} \mathrm{C}$ for $5 \mathrm{~min}$, then placed on ice for about $12 \mathrm{~min}$. The slides were denatured on a hot plate for $3 \mathrm{~min}$ at $91{ }^{\circ} \mathrm{C}$, then dehydrated in $70 \%, 80 \%$ and $100 \%$ ethanol for 2 min each step and allowed to air dry. The hybridization mixture was applied to the slides, covered with a glass coverslip and sealed with rubber cement. The hybridization proceeded at $37{ }^{\circ} \mathrm{C}$ for $18 \mathrm{hr}$ in a moisture chamber.

Following hybridization, the slides were washed two times at $43{ }^{\circ} \mathrm{C}$ in $50 \% \mathrm{FA} / 2 \times \mathrm{SSC}$ for $15 \mathrm{~min}$ each, followed by a 1 min wash in $2 \times \mathrm{SSC}$ at $20^{\circ} \mathrm{C}$. Next, $80 \mu \mathrm{L}$ of PNM blocking reagent $(5 \%$ non-fat dry milk in $0.1 \mathrm{M}$ sodium phosphate, $\mathrm{pH} 8.0,0.1 \%$ nonidet-P40, $0.1 \%$ sodium azide) were applied to each slide, slides were covered with a plastic coverslip and incubated at $20{ }^{\circ} \mathrm{C}$ for $5 \mathrm{~min}$. After removal of the coverslip, $80 \mu \mathrm{L}$ of detection buffer I (Vial 3, SKY ${ }^{\mathrm{TM}}$ kit, ASI) containing anti-dioxin antibodies raised in sheep (which cross-reacts with digoxigenin) $(5 \mu \mathrm{g} / \mathrm{mL}$ in $0.1 \%$ Tween $20 / 4 \times \mathrm{SSC}$, Roche) were added to each slide. The slides were then incubated at $20^{\circ} \mathrm{C}$ for $30 \mathrm{~min}$ and washed two times in $2 \times \mathrm{SSC}$ at $20{ }^{\circ} \mathrm{C}$ for $15 \mathrm{~min}$ each on a shaking platform. After a 5 min blocking step in PNM as before, $80 \mu \mathrm{L}$ of PNM buffer containing mouse-anti-sheep antibodies conjugated to Cy5.5 (5 $\mu \mathrm{g} / \mathrm{mL}$, Rockland Immunochemicals, Gilbertsville, PA) and avidin-FITC (20 $\mu \mathrm{g} / \mathrm{ml}$, Vector, Burlingame, CA) were applied to each slide, and slides were incubated at $20^{\circ} \mathrm{C}$ for $30 \mathrm{~min}$ in the dark. Slides were then washed two times in $2 \times \mathrm{SSC}$ at room temperature for $15 \mathrm{~min}$ each on a shaker. Finally, the slides were mounted in $10 \mu \mathrm{L}$ of DAPI (Vial 5, SKY ${ }^{\mathrm{TM}}$ kit) and coverslipped.

Specifically, for the discrimination of thyroid TPC-1 cancer cells known to express a chimeric form of the ret proto-oncogene [40,42] and MCF-7 breast cancer cells, we prepared a second set of cDNA probes targeting the six tk transcripts listed in Table 5. This probe set uses four fluorochromes coupled directly to the cDNA probes as reporter molecules, as well as biotin and digoxigenin, which were detected with Cy3.5-labeled avidin and Cy5.5-labeled anti-digoxigenin, respectively. Staining conditions have been described previously [43-45].

The cDNA clones used in the six transcript analysis, their accession numbers and insert sizes are listed in Table 6. These probes target two ephrin receptors (A1: EFNA1; A4: EFNA4) and the transcripts of the tk genes ABL, RON, BRK and RET. All cDNA clones, with the exception of RET, were from the I.M.A.G.E. consortium ('The Integrated Molecular Analysis of Genomes and their Expression'), Lawrence Livermore National Lab., Livermore, CA, distributed by Research Genetics. 
Table 5. cDNA targets and fluorochromes used in the seven-color, six RNA target spectral analysis.

\begin{tabular}{c|cccc}
\hline Target & Primary label & Secondary label & Excitation [nm] & Emission [nm] \\
\hline genomic DNA & DAP1 & - & 363 & 461 \\
RET & FITC & - & 495 & 528 \\
EFNA1 & CY3 & - & 552 & 565 \\
c-ABL & biotin & CY3.5 & 581 & 596 \\
EFNA4 & Texas Red & - & 596 & 620 \\
RON & CY5 & - & 650 & 667 \\
PTK6 & digoxigenin & CY5.5 & 678 & 703 \\
\hline
\end{tabular}

Table 6. cDNA clones used in the six-target FISH analysis.

\begin{tabular}{ccccc}
\hline $\begin{array}{c}\text { RNA } \\
\text { Target }\end{array}$ & $\begin{array}{c}\text { I.M.A.G.E. } \\
\text { clone ID }\end{array}$ & $\begin{array}{c}\text { Insert Size } \\
{[\mathbf{k b}]}\end{array}$ & $\begin{array}{c}\text { Genbank } \\
\text { Accession \# }\end{array}$ & $\begin{array}{c}\text { Fluorescent } \\
\text { Reporter }\end{array}$ \\
\hline EFNA1 & 320514 & 0.75 & W16661 & Cy3 \\
EFNA4 & 1942138 & 1.8 & XM_002578 & Texas Red \\
c-ABL & 1118140 & 2.2 & XM_001717 & Biotin*(Cy3.5) \\
RON & 2256805 & 3.3 & NM_002447 & Cy5 \\
PTK6 & 182934 & 0.6 & None & Digoxigenin* (Cy5.5) \\
RET & (PTC3) & 1.95 & None & FITC \\
\hline \multicolumn{7}{c}{ * Detected via incubation with avidin-Cy3.5 or antibodies against digoxin. }
\end{tabular}

\section{4. 'Spectral Un-mixing (SUN)' of High Resolution Images, Image Segmentation and Fluorescence} Integration to Measure Intracellular Levels of up to Six Fluorochromes

\subsubsection{Image Acquisition}

SIm combines the techniques of fluorescence microscopy, a charge-coupled device (CCD) camera and Fourier spectroscopy. Our system dedicated to image acquisition is comprised of a Zeiss Axioskope microscope (Zeiss, Oberkochen, Germany) equipped with a $150 \mathrm{~W}$ xenon light source (Ludl, Novato, CA, USA) and standard $40 \times, 63 \times$ and $100 \times$ oil immersion lenses for fluorescence microscopy (Zeiss), an ASI SD200 SpectraCubeTM spectral imaging system interferometer and a Vosskuehler (Osnabrueck, Germany) CCD camera. All images were acquired using the SpectraCube program (ASI). A second computer workstation runs a copy of SpectraView (Version 1.6, ASI) to allow off-line processing of spectral images. Both computers have the SkyView software (ASI) installed, which allows us to perform spectral karyotyping and spectral imaging analyses.

Images were acquired as described [18,28] using the spectral imaging software (ASI). Parameters were set to acquire spectral images from $450-800 \mathrm{~nm}$. The multiple band pass filter set used for fluorochrome excitation was custom-designed (SKY-1, Chroma Technology, Brattleboro, VT, USA) to provide broad emission bands (giving a fractional spectral reading from $\sim 450 \mathrm{~nm}$ to $\sim 850 \mathrm{~nm}$ ). Using a xenon light source, the spectral image was generated by acquiring 80-130 interferometric frames per object. Next, each interferogram was Fourier-transformed, producing the fluorescence spectrum for each pixel of the image. DAPI images were recorded using a DAPI specific optical filter set and stored as '.tiff' files. Sample emission spectra were measured in the visible and near-infrared spectral range simultaneously at all points in the microscopic image. For quality control, the spectral 
information was displayed by assigning red, green or blue (RGB) pseudo-colors to three areas of interest in the spectrum before the image stacks were archived.

\subsubsection{Digital Image Analysis}

Digital image analysis using the SkyView software (ASI) (i.e., the spectral classification of physically separated objects) could be done on either of our computer systems. Spectral analysis to determine the relative intracellular amounts of reporter molecules required the SpectraView software (ASI) and is a rather time-consuming process. In order to avoid bottlenecks at the microscope and image acquisition station, this analysis was done offline on a separate computer workstation. For the present studies, reference spectra libraries were built by recording the fluorescence emission spectra of pure dyes as described [26,28,32]. Data management was facilitated through the use of Case Manager software (ASI), which is a databasing program based on Microsoft Access (Microsoft Inc., Seattle, WA, USA).

The typical analysis procedure involved creation of a case record in which all relevant information, as well as comments, were stored. The spectral image was then loaded and displayed according to the settings of the RGB-display manager. SpectraView allows us to define up to 9 reference spectra plus a background spectrum for analysis. The common steps in the interactive analysis are comprised of definition and subtraction of background fluorescence, definition or import of reference spectra recorded from pure dyes and spectral un-mixing (SUN) to resolve the spectral image into its spectral constituents.

To obtain quantitative information, the user defines one or several regions of interest (ROI). The SpectraView software allows the user to enter an ROI manually or to use a 'seed' ROI and have the program find areas of similar intensity and/or spectral composition. The software will then analyze each pixel within the ROI and attempt to deconvolute the measured spectrum to match the reference spectra. Results are reported as ROI area and average pixel intensity, as well as the relative contribution of each of the reference spectra to the total intensity. The present version of the software reports occasional negative values for the relative contribution. These values will be reported as zeros in future releases.

Initially, we used five fluorochromes (FITC, Cy3, Texas Red, Cy5 and Cy5.5) to detect and quantitate gene-specific transcripts in individual cells. The fluorochromes were chosen to match the SKY-1 filter set and were used very successfully in our SKY and spectral imaging studies to label individual chromosomes in interphase or metaphase cells [32]. Genomic DNA was counterstained with DAPI, bringing the total number of colors to six. However, DAPI images had to be acquired using a DAPI-specific filter set (ChromaTechnology). The RNA targets and labels, as well as excitation and emission characteristics, of the fluorochromes are summarized in Tables 4-5. This set-up allowed us to optimize hybridization and staining conditions. We noted that the signals faded during the time it took to record a full spectrum. We thus decided to use fluorescent beads in initial experiments to investigate the system reproducibility. All fluorescent beads were purchased from Molecular Probes (Eugene, OR, USA). We used four kinds of beads from the Inspeck $^{\mathrm{TM}}$ series (3\% dye load, 2.5 micron) with fluorescence colors described as green orange, red and deep red (Table 3). One of the excitation bands of the SKY-1 filter set (ChromaTechnology) is centered around $640 \mathrm{~nm}$. To achieve our goal of five different fluorescence colors, we added one of the three beads with infrared fluorescence (Crimson, Scarlet, Ultra Red; Molecular Probes; Table 3). The emission characteristics of the beads are listed in Table 3. The largest beads available with 'Crimson' fluorescence were $1 \mu \mathrm{m}$ Fluosphere ${ }^{\circledR}$ beads. 


\section{Conclusions}

The analysis of RNA transcript levels by conventional methods [46,47] or using high density cDNA microarrays [2] provides a wealth of information expected to lead to new clues to carcinogenic processes. Because of the complex and heterogeneous nature of most tumor samples, histochemical techniques, particularly RNA fluorescence in situ hybridization (FISH), are required to test predictions from cDNA microarray expression experiments.

Preliminary studies performed in our lab and elsewhere indicated that solid tumors are heterogeneous with respect to oncogene expression. To address this problem, we are developing an innovative system to simultaneously measure cell-by-cell levels of multiple tumor markers. Our approach to multi-color analysis of RNA expression levels using high resolution spectral imaging and digital image analysis has proven to possess the sensitivity, specificity and reproducibility required to detect tumor cells with an abnormal pattern of tk gene expression at frequencies as low as one in a hundred cells. This system, capable of deconvoluting images captured from objects stained with probes carrying one of multiple fluorochromes, was initially tested with fluorescent beads. We then used it to analyze the expression levels of five-to-six different tk genes in MCF-7 breast cancer or TPC-1 cells. Results demonstrate that the SIm system is well qualified to resolve signals from different targets, and quite simple image processing algorithms allow tumor cell classification.

It should be noted that the SPECTRA approach and quantitative PCR (qPCR) complement one another. As shown in the examples above, SPECTRA allows a simultaneous measurement of the amounts and intracellular distribution of several protein-coding or noncoding RNA transcripts and reveals their spatial relationships. The qPCR approach to measure transcriptional levels provides average values over the sample sizes. While it appears straightforward to extend the applications of SPECTRA to the multi-transcript analysis of tissue sections, qPCR following tissue microdissection provides rapid means to study the distribution of single gene expression in tissue sections. Compared to qPCR, SPECTRA analysis offers a lower sample throughput and relies on expensive multi-spectral imaging equipment.

\section{Acknowledgments}

This work was supported in part by NIH grants CA88258, CA80792 and CA136685 (to HUW) and a grant from the Director, Office of Energy Research, Office of Health and Environmental Research, U.S. Department of Energy, under contract DE-AC-02-05CH11231 and a grant from the Breast Cancer Research Program, U.S. Army Medical Research and Material Command, U.S. Department of the Army. JFW was supported by NIH grants HD44313 and HD45736. We are grateful to N. Satoh, Cancer Research Institute, Kanazawa University, Japan, and J. Garbe, LBNL, for providing the TPC-1 and 184A1TH cells, respectively.

\section{Disclaimer}

This document was prepared as an account of work sponsored by the United States Government. While this document is believed to contain correct information, neither the United States Government nor any agency thereof, nor The Regents of the University of California, nor any of their employees, 
make any warranty, express or implied, or assumes any legal responsibility for the accuracy, completeness or usefulness of any information, apparatus, product or process disclosed, or represent that its use would not infringe privately owned rights. Reference herein to any specific commercial product, process or service by its trade name, trademark, manufacturer or otherwise does not necessarily constitute or imply its endorsement, recommendation or favoring by the United States Government or any agency thereof or The Regents of the University of California. The views and opinions of the authors expressed herein do not necessarily state or reflect those of the United States Government or any agency thereof or The Regents of the University of California.

\section{Conflict of Interest}

The authors declare no conflict of interest.

\section{References}

1. Lersch, R.A.; Fung, J.; Hsieh, H.B.; Smida, J.; Weier, H.U. Monitoring signal transduction in cancer: from chips to fish. J. Histochem. Cytochem. 2001, 49, 925-926.

2. Weier, H.; Munne, S.; Lersch, R.A.; Hsieh, H.; Smida, J.; Chen, X.; Korenberg, J.R.; Pedersen, R.A.; Fung, J. Towards a full karyotype screening of interphase cells: 'FISH and chip' technology. Mol. Cell. Endocrinol. 2001, 183(Suppl. 1), S41-S45.

3. Iourov, I.Y.; Vorsanova, S.G.; Yurov, Y.B. Chromosomal mosaicism goes global. Mol. Cytogenet. 2008, 1, 26.

4. Iourov, I.Y.; Vorsanova, S.G.; Yurov, Y.B. Somatic genome variations in health and disease. Curr. Genomics 2010, 11, 387-396.

5. Chapman, J.A.; Wolman, E.; Wolman, S.R.; Remvikos, Y.; Shackney, S.; Axelrod, D.E.; Baisch, H.; Christensen, I.J.; White, R.A.; Liebovitch, L.S.; Moore, D.H.; Waldman, F.M.; Cornelisse, C.J.; Shankey, T.V. Assessing genetic markers of tumour progression in the context of intratumour heterogeneity. Cytometry 1998, 31, 67-73.

6. Trakhtenbrot, L.; Cohen, N.; Rosner, E.; Gipsh, N.; Brok-Simoni, F.; Mandel, M.; Amariglio, N.; Rechavi, G. Coexistence of several unbalanced translocations in a case of neuroblastoma: the contribution of multicolor spectral karyotyping. Cancer Genet. Cytogenet. 1999, 112, 119-123.

7. Yurov, Y.B.; Iourov, I.Y.; Monakhov, V.V.; Soloviev, I.V.; Vostrikov, V.M.; Vorsanova, S.G. The variation of aneuploidy frequency in the developing and adult human brain revealed by an interphase FISH study. J. Histochem. Cytochem. 2005, 53, 385-390.

8. Yurov, Y.B.; Iourov, I.Y.; Vorsanova, S.G.; Demidova, I.A.; Kravetz, V.S.; Beresheva, A.K.; Kolotii, A.D.; Monakchov, V.V.; Uranova, N.A.; Vostrikov, V.M.; Soloviev, I.V.; Liehr, T. The schizophrenia brain exhibits low-level aneuploidy involving chromosome 1. Schizophr. Res. 2008, 98, 139-147.

9. Yurov, Y.B.; Vorsanova, S.G.; Iourov, I.Y. Ontogenetic variation of the human genome. Curr. Genomics 2010, 11, 420-425.

10. Jossart, G.H.; Clark, O.H. Well-differentiated thyroid cancer. Curr. Probl. Surg. 1994, 31, 933-1012.

11. Nikiforov, Y.E. Genetic alterations involved in the transition from well-differentiated to poorly differentiated and anaplastic thyroid carcinomas. Endocr. Pathol. 2004, 15, 319-327. 
12. Aktas, D.; Utine, E.G.; Mrasek, K.; Weise, A.; von Eggeling, F.; Yalaz, K.; Posorski, N.; Akarsu, N.; Alikasifoglu, M.; Liehr, T.; Tuncbilek, E. Derivative chromosome 1 and GLUT1 deficiency syndrome in a sibling pair. Mol. Cytogenet. 2010, 3, 10.

13. Lee, T.K. The value of imprint cytology in tumor diagnosis: a retrospective study of 522 cases in northern China. Acta Cytol. 1982, 26, 169-171.

14. Liu, Y.; Silverman, J. F.; Sturgis, C.D.; Brown, H.G.; Dabbs, D.J.; Raab, S.S. Utility of intraoperative consultation touch preparations. Diagn. Cytopathol. 2002, 26, 329-333.

15. Wang, J.Q. Analysis of mRNA expression using double in situ hybridization labeling with isotopic and nonisotopic probes. Methods Mol. Med. 2003, 79, 153-159.

16. Williams, S.V.; Platt, F.M.; Hurst, C.D.; Aveyard, J.S.; Taylor, C.F.; Pole, J.C.; Garcia, M.J.; Knowles, M.A. High-resolution analysis of genomic alteration on chromosome arm $8 \mathrm{p}$ in urothelial carcinoma. Genes Chromosomes Cancer 2010, 49, 642-659.

17. Fabien, N.; Paulin, C.; Santoro, M.; Berger, N.; Grieco, M.; Galvain, D.; Barbier, Y.; Dubois, P.M.; Fusco, A. Detection of RET oncogene activation in human papillary thyroid carcinomas by in situ hybridisation. Br. J. Cancer 1992, 66, 1094-1098.

18. Garini, Y.; Macville M.; du Manoir, S.; Buckwald, R.A.; Lavi, M.; Katzir, N.; Wine, D.; Bar-Am, I.; Schröck, E.; Cabib, D.; Ried, T. Spectral karyotyping. Bioimaging 1996, 4, 65-72.

19. Garini, Y.; Gil, A.; Bar-Am, I.; Cabib, D.; Katzir, N. Signal to noise analysis of multiple color fluorescence imaging microscopy. Cytometry 1999, 35, 214-226.

20. Levenson, R.M.; Hoyt, C.C. Spectral Imaging and microscopy. Am. Lab. 2000, 32, 26-34.

21. Macville, M.V.; Van der Laak, J.A.; Speel, E.J.; Katzir, N.; Garini, Y.; Soenksen, D.; McNamara, G.; de Wilde, P.C.; Hanselaar, A.G.; Hopman, A.H.; Ried, T. Spectral imaging of multi-color chromogenic dyes in pathological specimens. Anal. Cell. Pathol. 2001, 22, 133-142.

22. Dickinson, M.E.; Bearman, G.; Tille, S.; Lansford, R.; Fraser, S.E. Multi-spectral imaging and linear unmixing add a whole new dimension to laser scanning fluorescence microscopy. BioTechniques 2001, 31, 1272, 1274-1276, 1278.

23. Levenson, R.M.; Lynch, D.T.; Kobayashi, H.; Backer, J. M.; Backer, M.V. Multiplexing with multispectral imaging: from mice to microscopy. ILAR J. 2008, 49, 78-88.

24. Malik, Z.; Cabib, D.; Buckwald, R.A.; Talmi, A.; Garini, Y.; Lipson, S.G. Fourier transform multipixel spectroscopy for quantitative cytology. J. Microsc. 1996, 182, 133-140.

25. Garini, Y.; Katzir, N.; Cabib, D.; Buckwald, R.A.; Soenksen, D.G.; Malik, Z., Spectral bioimaging. In Fluorescence Imaging Spectroscopy and Microscopy; Wang, X.F., Herman, B., Eds. John Whiley \& Sons: New York, USA, 1996; Vol. 137, pp. 87-124.

26. Schroeck, E.; du Manoir, S.; Veldman, T.; Schoell, B.; Wienberg, J.; Ferguson-Smith, M.A.; Ning, Y.; Ledbetter, D.H.; Bar-Am, I.; Soenksen, D.; Garini, Y.; Ried, T. Multicolor spectral karyotyping of human chromosomes. Science 1996, 273, 494-497.

27. Veldman, T.; Vignon, C.; Schroeck, E.; Rowley, J.D.; Ried, T. Hidden chromosome abnormalities in haematological malignancies detected by multicolour spectral karyotyping. Nat. Genet. 1997, $15,406-410$.

28. Fung, J.; Hyun, W.; Dandekar, P.; Pedersen, R.A.; Weier, H.U. Spectral imaging in preconception/preimplantation genetic diagnosis of aneuploidy: multicolor, multichromosome screening of single cells. J. Assist. Reprod. Genet. 1998, 15, 323-330. 
29. Marquez, C.; Cohen, J.; Munne, S. Chromosome identification in human oocytes and polar bodies by spectral karyotyping. Cytogenet. Cell Genet. 1998, 81, 254-258.

30. Zitzelsberger, H.; Lehmann, L.; Hieber, L.; Weier, H.U.; Janish, C.; Fung, J.; Negele, T.; Spelsberg, F.; Lengfelder, E.; Demidchik, E.P.; Salassidis, K.; Kellerer, A.M.; Werner, M.; Bauchinger, M. Cytogenetic changes in radiation-induced tumors of the thyroid. Cancer Res. 1999, 59, 135-140.

31. Ning, Y.; Laundon, C. H.; Schroeck, E.; Buchanan, P.; Ried, T. Prenatal diagnosis of a mosaic extra structurally abnormal chromosome by spectral karyotyping. Prenat. Diagn. 1999, 19, 480-482.

32. Fung, J.; Weier, H.U.G.; Goldberg, J.D.; Pedersen, R.A. Chromosome enumeration in interphase amniocytes using Spectral Imaging. Hum. Genet. 2000, 107, 615-622.

33. Zitzelsberger, H.; Bruch, J.; Smida, J.; Hieber, L.; Peddie, C.M.; Bryant, P.E.; Riches, A.C.; Fung, J.; Weier, H.U.; Bauchinger, M. Clonal chromosomal aberrations in simian virus 40-transfected human thyroid cells and in derived tumors developed after in vitro irradiation. Int. J. Cancer 2001, 96, 166-177.

34. Liehr, T.; Ewers, E.; Kosyakova, N.; Klaschka, V.; Rietz, F.; Wagner, R.; Weise, A. Handling small supernumerary marker chromosomes in prenatal diagnostics. Expert Rev. Mol. Diagn. 2009, 9, 317-324.

35. Nederlof, P.M.; van der Flier,S.; Wiegant, J.; Raap, A.K.; Tanke, H.J.; Ploem, J.S.; van der Ploeg, M. Multiple fluorescence in situ hybridization. Cytometry 1990, 11, 126-131.

36. Fan, Y.S.; Siu, V.M.; Jung, J.H.; Xu, J. Sensitivity of multiple color spectral karyotyping in detecting small interchromosomal rearrangements. Genet. Test. 2000, 4, 9-14.

37. Greulich, K.M.; Kreja, L.; Heinze, B.; Rhein, A.P.; Weier, H.G.; Bruckner, M.; Fuchs, P.; Molls, M. Rapid detection of radiation-induced chromosomal aberrations in lymphocytes and hematopoietic progenitor cells by mFISH. Mutat. Res. 2000, 452, 73-81.

38. Machikhin, A.S.; Pozhar, V.E. Method for correcting spectral distortions for spectrometer images. Instr. Exp. Techn. 2009, 6, 92-98.

39. Lee, C.; Gisselsson, D.; Jin, C.; Nordgren, A.; Ferguson, D.O.; Blennow, E.; Fletcher, J.A.; Morton, C.C. Limitations of chromosome classification by multicolor karyotyping. Am. J. Hum. Genet. 2001, 68, 1043-1047.

40. Jossart, G.H.; Greulich, K.M.; Siperstein, A.E.; Duh, Q.; Clark, O.H.; Weier, H.U. Molecular and cytogenetic characterization of a $\mathrm{t}(1 ; 10 ; 21)$ translocation in the human papillary thyroid cancer cell line TPC-1 expressing the ret/H4 chimeric transcript. Surgery 1995, 118, 1018-1023.

41. Stampfer, M.R.; Bartley, J.C. Induction of transformation and continuous cell lines from normal human mammary epithelial cells after exposure to benzo[a]pyrene. Proc. Natl. Acad. Sci. USA 1985, 82, 2394-2398.

42. Ishizaka, Y.; Itoh, F.; Tahira, T.; Ikeda, I.; Ogura, T.; Sugimura, T.; Nagao, M. Presence of aberrant transcripts of ret proto-oncogene in a human papillary thyroid carcinoma cell line. Jpn. J. Cancer Res. 1989, 80, 1149-1152.

43. Jossart, G. H.; O'Brien, B.; Cheng, J.F.; Tong, Q.; Jhiang, S.M.; Duh, Q.; Clark, O.H.; Weier, H.U. A novel multicolor hybridization scheme applied to localization of a transcribed sequence (D10S170/H4) and deletion mapping in the thyroid cancer cell line TPC-1. Cytogenet. Cell Genet. 1996, 75, 254-257. 
44. Zitzelsberger, H.F.; O'Brien, B.; Weier, H.-U.G. Multicolor FISH techniques for the detection of inter- and intrachromosomal rearrangements. In FISH Technology; Rautenstrauss, B., Liehr, T., Eds.; Springer Verlag: Heidelberg, Germany, 2002; pp. 408-424.

45. O'Brien, B.; Jossart, G.H.; Ito, Y.; Greulich-Bode, K.M.; Weier, J.F.; Munne, S.; Clark, O.H.; Weier, H.U.G. 'Chromosomal Rainbows' detect oncogenic rearrangements of signaling molecules in thyroid tumors. Open Cell Signal. J. 2010, 2, 13-21.

46. Deng, J.; Tan, L.; Lin, X.; Lu, Y.; Lu, L.J. Exploring the optimal strategy to predict essential genes in microbes. Biomolecules 2012, 2, 1-22.

47. Holmes, R.S. Comparative studies of vertebrate platelet glycoprotein 4 (CD36). Biomolecules 2012, 2, 389-414.

(C) 2013 by the authors; licensee MDPI, Basel, Switzerland. This article is an open access article distributed under the terms and conditions of the Creative Commons Attribution license (http://creativecommons.org/licenses/by/3.0/). 